\title{
Análise dos determinantes do endividamento das empresas de capital aberto do agronegócio brasileiro
}

\author{
Valéria Gama Fully Bressan ${ }^{1}$ \\ João Eustáquio de Lima² \\ Aureliano Angel Bressan ${ }^{3}$ \\ Marcelo José Braga ${ }^{4}$
}

Resumo: Estudos sobre a estrutura de capital e a identificação de seus determinantes são temas relevantes nas pesquisas envolvendo a gestão financeira das empresas. Neste aspecto, o presente estudo teve como objetivo avaliar os determinantes da alavancagem das empresas do agronegócio brasileiro conforme o modelo de Rajan e Zingales (1995). Na definição da amostra, foram selecionadas 26 empresas que estavam enquadradas em alguma das três subdivisões do agronegócio brasileiro: a) o setor de produção agropecuária; b) setor fornecedor de insumos e fatores de produção e c) setor de processamento e distribuição, com base em classificação da CNA (Confederação da Agricultura e Pecuária do Brasil). O estudo foi feito com base no banco de dados da Economática ${ }^{\circledR}$, tendo sido utilizado o modelo de regressão com dados em painel. Os resultados indicaram que as variáveis tangibilidade dos ativos, oportunidade

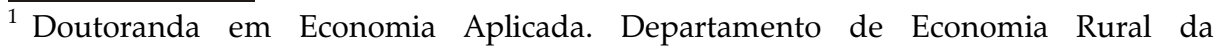
Universidade Federal de Viçosa (UFV). E-mail: valeria.fully@gmail.com

${ }^{2}$ Professor do Departamento de Economia Rural da Universidade Federal de Viçosa (DER-UFV). Pós-Doutor pela University of Florida e Doutor em Economia Rural pela Michigan State University. E-mail: jelima@ufv.br

${ }^{3}$ Doutor em Economia Aplicada. Professor Adjunto da Faculdade de Ciências Econômicas da Universidade Federal de Minas Gerais (UFMG). E-mail: bressan@face.ufmg.br

${ }^{4}$ Pós-Doutorado na University of Califórnia at Davis. Professor Adjunto do Departamento de Economia Rural. Pesquisador do CNPQ. E-mail: mjbraga@ufv.br 
- Análise dos determinantes do endividamento das empresas de capital aberto do agronegócio brasileiro

de crescimento, tamanho e lucratividade foram estatisticamente significantes e podem ser interpretadas como fatores determinantes do endividamento das empresas do agronegócio brasileiro. Conclui-se, ainda, que o modelo estimado por meio da regressão com dados em painel gerou resultado compatível com aqueles preconizados pela pecking order theory.

Palavras-chaves: Endividamento, estrutura de capital, agronegócio, Pecking Order Theory.

Classificação JEL: Q14, G32.

Abstract: Studies involving capital structure and the identification of its determinants are relevant issues in the field of corporate finance management research. In this regard, the present study intends to evaluate the determinants of corporate leverage in the Brazilian agribusiness sector using the model of Rajan and Zingales (1995). In the definition of the sample there were selected 26 companies that are classified in one of three subdivisions of the Brazilian agribusiness sector: a) the agriculture or cattle raising; $b$ ) inputs or production factors and c) processing and distribution sector, using as reference the CNA classification. The study used data from the Economatica ${ }^{\circledR}$ database, with the adoption of panel data methods. The results indicated that the variables tangibility of assets, growth opportunities, size and profitability were statiscally significant as determinant factors of the debt structure of Brazilian agribusiness companies. It is also possible to conclude that the model estimated by panel data generated results that are compatible with those suggested by the pecking order theory.

Key-words: Debt, capital structure, agribusiness, Pecking Order Theory.

JEL Classification: Q14, G32.

\section{Introdução}

O agronegócio brasileiro tem-se mostrado representativo no cenário nacional como segmento relevante na geração de divisas e emprego. Conforme dados do IBGE (2006), em 2003, pelo terceiro ano consecutivo, a taxa de crescimento da agroindústria superou a da 
indústria em geral, tendo registrado o crescimento de $1,6 \%$, enquanto a taxa obtida pela média da indústria nacional foi de $0,3 \%$ no mesmo período. Resultado que confirma o impacto positivo originado do agronegócio, principalmente o de exportação, sobre a atividade industrial (IBGE, 2006).

Além de manter seus parceiros tradicionais, o agronegócio brasileiro ampliou mercados e expandiu os itens da pauta de exportação. Em 2000, havia uma concentração de $18,1 \%$ do comércio do agronegócio com os Estados Unidos que, em 2005, caiu para 13,7\%. A estratégia brasileira de manter os parceiros tradicionais e ao mesmo tempo conquistar novos mercados e ampliar a pauta de exportações do setor fez com que o número de mercados para os produtos agropecuários brasileiros passasse de 182 países em 2000 para 214 em 2005. Ano este que produtos agropecuários foram responsáveis por $66 \%$ das exportações brasileiras para países árabes (SRB, 2006).

Corroboram estas informações o fato de as 400 maiores empresas do agronegócio responderem conjuntamente por uma renda de 370 bilhões de reais em 2005, montante que representa metade de tudo que é produzido no Brasil pelo setor (JAEL, 2006).

Sendo assim, esta pesquisa versará sobre as empresas do agronegócio brasileiro, setor que, de forma ampla, engloba todas as organizações direta ou indiretamente ligadas à atividade agropecuária brasileira, quais sejam: o setor de produção agropecuária, o setor fornecedor de insumos e fatores de produção e o setor de processamento e distribuição.

O presente artigo está estruturado da seguinte forma: a seguir apresenta-se o problema, o objetivo e a justificativa da pesquisa. A segunda parte consiste no referencial teórico, que versará sobre endividamento, estrutura de capital e o modelo de Rajan e Zingales (1995). O terceiro tópico discute os aspectos metodológicos que se subdividem em coleta de dados, unidades de análise, caracterização das variáveis e o modelo analítico. Por fim, discutem-se os resultados da pesquisa e, logo em seguida, são apresentadas as conclusões.

\subsection{Problema de Pesquisa e Objetivo do Estudo}

A questão do endividamento ótimo ainda é considerada uma questão não plenamente resolvida no campo da gestão financeira das empresas, em que pese o grande desenvolvimento 
que a teoria de estrutura de capital apresentou desde os trabalhos pioneiros de Modigliani e Miller (1958, 1963). Entretanto, tem sido objeto de estudo em muitos países quais são as variáveis que de forma mais relevante explicam a forma como as empresas definem sua política de endividamento (NAKAMURA, MARTIN e KIMURA, 2004, p.1).

Buscar-se-á responder o seguinte questionamento: Quais os determinantes da alavancagem das empresas do agronegócio brasileiro conforme o modelo de Rajan e Zingales (1995)?

Dada a importância estratégica do setor para a economia nacional, o objetivo geral desta pesquisa é analisar as características da estrutura de capital das empresas do agronegócio listadas na Bovespa, investigando as relações existentes entre o nível de endividamento e os fatores apontados pela teoria como seu determinante.

\subsection{Justificativa}

Inicialmente, a expressividade do setor justifica uma análise mais detalhada do mesmo, em especial, dos determinantes da estrutura de endividamento destas empresas nele inseridas. Pois, de acordo com Soares e Kloeckner (2005, p.1)

a estrutura de capital das empresas tem sido um dos principais temas de pesquisas na área de finanças corporativas. Diversos estudos têm tentado explicar as decisões de financiamento e endividamento da empresa e os impactos gerados por tais decisões. Por ser um tema controverso, tem permitido enfoques distintos, por diferentes correntes teóricas. Os testes empíricos destas diversas vertentes, entretanto, têm conduzido a resultados divergentes.

A análise por setor é considerada uma variável relevante para explicar a estrutura financeira das empresas conforme Ferri e Jones (1979), Bradley, Jarrell e Kim (1984), Titman e Wessels (1988), Scott (1972) e Scott e Martin (1976) citados por Nakamura, Martin e Kimura (2004).

Destaca-se que o tema em questão vem sendo discutido por inúmeros autores que serão mencionados ao longo deste trabalho. Todavia, constatou-se que apenas Oliveira e Antonialli (2004) estudaram a estrutura de capital das empresas do agronegócio brasileiro. Estes autores 
realizaram uma pesquisa descritiva, utilizando análise de cluster, para uma amostra intencional de 69 empresas agroindustriais localizadas no sul de Minas Gerais.

De acordo com Fassina, Hein e Olinquevitch (2006), o endividamento geral das 500 maiores empresas do Brasil vinha apresentando até o ano de 2002 constantes aumentos. Já a partir do ano de 2003, o nível de endividamento das referidas empresas começou a apresentar sinais de recuo, fazendo com que, em 2004, retornasse aos patamares apresentado na virada do século. Com isso, houve um equilíbrio da utilização do capital de terceiros em relação ao capital próprio, demonstrando que as empresas brasileiras redobraram os cuidados com seus passivos num cenário marcado principalmente pelos altos juros impostos pela política econômica.

Numa análise mais recente, conforme IEDI (2006), as grandes empresas industriais brasileiras melhoraram os níveis e a qualidade do seu endividamento nos seis primeiros meses de 2006. O endividamento líquido sobre o patrimônio líquido, do total de uma amostra de 101 empresas industriais selecionadas, passou de 0,45 para 0,34 entre junho de 2005 e junho de 2006 (e de 0,46 para 0,42 não considerando a Petrobras, maior empresa da amostra no conjunto das empresas pesquisadas) e o percentual do endividamento de curto prazo no endividamento total aumentou de 0,27 para 0,29 no mesmo período. No entanto, sem considerar a Petrobras este percentual apresentou o mesmo patamar de toda a amostra, passando de 0,32 para 0,29 , no período de julho de 2005 a junho de 2006.

De acordo como o mesmo instituto, para o melhor entendimento da dinâmica do endividamento e do resultado das empresas industriais brasileiras, é importante verificar o comportamento da taxa de câmbio. Esta variável influencia o desempenho das empresas que possuem endividamento atrelado à variação cambial e daquelas cujo destino principal é as exportações (IEDI, 2006).

Por este motivo, optou-se por utilizar os dados das empresas do agronegócio listadas na Bovespa a partir de 1999, visto que esse é o período com maiores alterações na taxa de câmbio se comparado com anos anteriores, como pode-se notar pela Figura 1. 
- Análise dos determinantes do endividamento das empresas de capital aberto do agronegócio brasileiro

Figura 1. Taxas de câmbio no Brasil, no período de $1^{\text {O }}$ de janeiro de 1992 a 28 de setembro de 2006

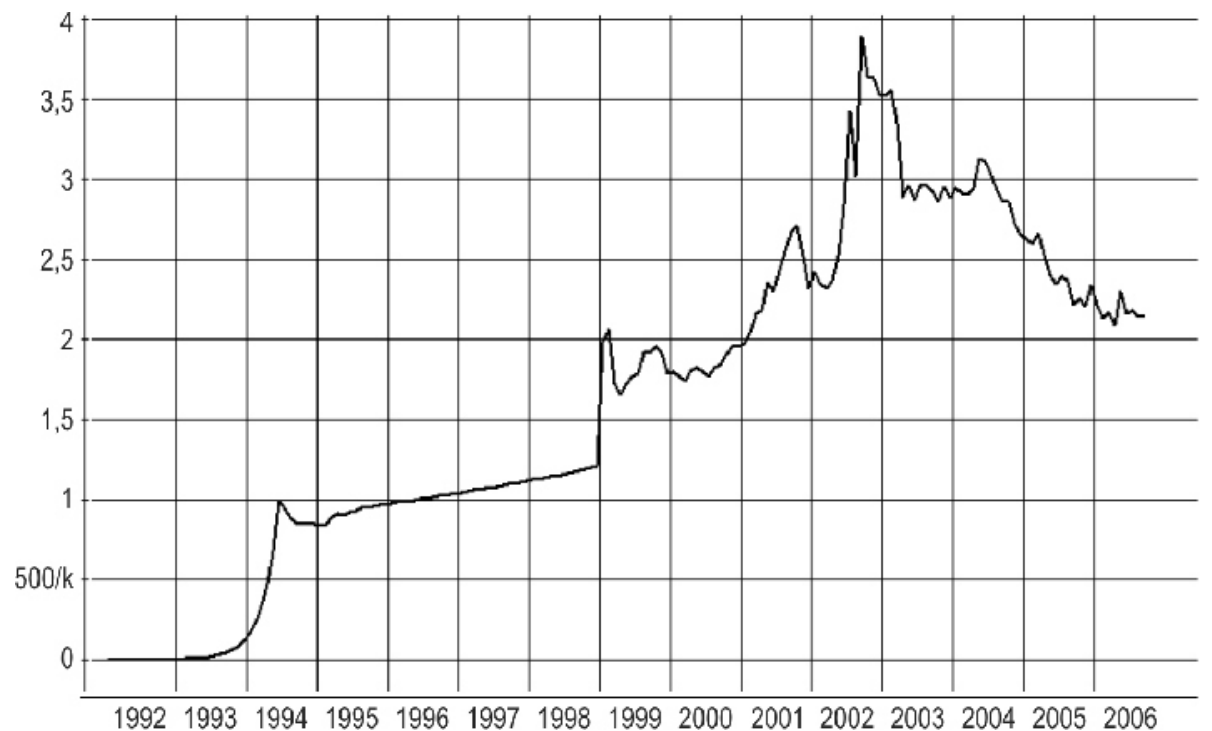
Fonte: Economática ${ }^{\circledR}$

\section{Referencial Teórico}

\subsection{Endividamento}

Conforme Nakamura, Martin e Kimura (2004, p.1), "endividamento é um aspecto importante da análise financeira de empresas não financeiras, especialmente em economias como a brasileira, que possuem características peculiares que as tornam menos favoráveis à prática voluntária de políticas de financiamento."

O campo que estuda o endividamento é denominado de estrutura de capital. Entende-se como estrutura de capital a forma como a empresa compõe o lado direito do seu balanço patrimonial, em termos de capital próprio e capital de terceiros.

Existem pelo menos duas versões de estrutura de capital, conforme Brealey e Myers (2003) apud Nakamura, Martin e Kimura (2004). Uma considera somente as dívidas de longo prazo. Outra considera tanto as dívidas de longo, quanto de curto prazo. No presente trabalho, serão utilizadas ambas as versões para avaliação da estrutura de capital das empresas do agronegócio brasileiro. 
Consideramos que ambas as posições são defensáveis, principalmente se considerarmos que dívidas de curto prazo, quando sistematicamente renegociadas, tornam-se recursos permanentes usados pela empresa (NAKAMURA, MARTIN E KIMURA, 2004, p. 3).

Outro aspecto que merece ser considerado é quanto ao cálculo do endividamento da empresa, levando em conta valores contábeis ou considerando valores de mercado. Ambos os cálculos são utilizados em vários estudos sobre endividamento, a saber: Bradley, Jarrell e Kim (1984), Rajan e Zingales (1995), Daher (2004), entre outros.

Neste estudo, dentre as possibilidades de critérios de endividamento discutidas na literatura contábil e financeira, enumeradas a seguir, optou-se por utilizar as medidas de endividamento de Daher (2004).

I. Marsh (1982): a) Divida de longo prazo = Dívida de longo prazo + ações preferenciais / capital total.; b) Divida de curto prazo $=$ Dívida de curto prazo/financiamentos totais.

II. Titman e Wessels (1988): a) Dívidas de curto-prazo; b) Dívidas de longo-prazo e c) Debêntures conversíveis.

III. Matarazzo (1988): a) Participação de capital de terceiros = capital de terceiros/ patrimônio líquido; b) Composição do endividamento = passivo circulante/ capital de terceiros; c) Imobilização do patrimônio líquido = ativo permanente/patrimônio líquido; e d) Imobilização dos recursos não correntes $=$ ativo permanente/ patrimônio líquido + exigível a longo prazo.

IV. Rajan e Zingales (1995): a) Alavancagem = total do passivo/total dos ativos; b) Dívida Totais (curto e longo prazos/Ativos Totais ou Ativos Líquidos); c) Dívida Total (curto e longo prazos/Dívidas totais + valor de mercado das ações) e d) Índice de cobertura de juros.

V. Kayo e Famá (1997): a) Endividamento sobre ativo total contábil = valor total das dívidas financeiras /ativo total contábil; b) Endividamento sobre o valor de mercado $=$ valor total das dívidas financeiras / valor total de mercado da empresa.

VI. Hovakimian, Opler e Titman (2001): a) Alavancagem = dívidas totais/valor contábil das dívidas + valor de mercado das ações.

VII. Booth et. al. (2001): a) Endividamento = exigibilidades totais/ exigibilidades totais + patrimônio líquido; b) Alavancagem $=$ obrigações de longo prazo/obrigações de longo prazo + 
patrimônio líquido; e c) Alavancagem = obrigações de longo prazo/obrigações de longo prazo + valor de mercado das ações.

VIII. Baker e Wurgler (2001): a) Endividamento contábil = dívidas totais em termos contábeis/ativos totais, $b$ ) Endividamento de mercado $=$ valor contábil das dívidas /ativos totais - valor patrimonial das ações + valor de mercado das ações.

IX. Ross, Westerfiel e Jaffe (2002): a) Total das dívidas/ total dos ativos; b) Total das dívidas/ patrimônio líquido; c) Multiplicador de capital próprio $=$ Total dos ativos/ patrimônio líquido e d) Cobertura de juros $=$ LAJIR/ Despesas com juros.

X. Gitman (2002) e Weston e Brigham (2000): a) Endividamento Geral = exigível total/ ativo total; b) Exigível a longo prazo/ patrimônio líquido; c) Cobertura de juros = LAJIR $/$ despesa anual com juros e d) Cobertura de pagamentos fixos = LAJIR + pgto por leasing/ juros + pgto por leasing $+\{$ (amortizações do principal + DivPref $)$ $x[(1 /(1-\mathrm{T})]\}$.

XI. Assaf Neto (2003): a) Capital de Terceiros/Capital Próprio; b) Capital de Terceiros/ Passivo Total; c) Imobilização de recursos permanentes = ativo permanente/ exigível a longo prazo + patrimônio Líquido.

XII. Daher (2004): a) Dívida total / Ativo líquido; b) Dívida total/ Valor de mercado das ações + total do passivo oneroso; c) Dívida total /Ativo total; d) Dívida total/ Patrimônio líquido + total do passivo oneroso; e) Dívida de longo prazo / Ativo líquido; f) Dívida de longo prazo/ Valor de mercado das ações + passivo oneroso de longo prazo; g) Dívida de longo prazo/ Ativo total e h) Dívida de longo prazo/ Patrimônio líquido + passivo oneroso de longo prazo.

XIII. Damodaran (2004): a) Índice de dívida para capital = dívida/ dívida + patrimônio líquido; b) Índice de dívida para patrimônio = dívida / patrimônio líquido; c) Índice de dívida de valor de mercado para o capital $=$ Valor de Mercado da dívida + Valor de Mercado do patrimônio líquido; d) Índice de dívida de valor de mercado para o patrimônio líquido = Valor de Mercado do patrimônio líquido.

XIV. Marion (2005): a) Capital de Terceiros/ Passivo Total; b) Capital Próprio/Capital de Terceiros e c) Composição do endividamento.

A seguir serão apresentadas, brevemente, as principais fundamentações teóricas sobre estrutura de capital. 


\subsection{Estrutura de Capital}

As teorias de estrutura de capital atentam para a importância da decisão de financiamento das firmas, relaxando a hipótese da eficiência dos mercados e destacando o efeito de alguma imperfeição sobre a escolha da estrutura ótima de capital, particularmente a presença de assimetria de informação. Por um lado, a teoria de static tradeoff5 (STT) defende que as firmas estabelecem uma meta ótima de endividamento. Por outro, a teoria da pecking $\operatorname{order}^{6}$ (POT) argumenta que as decisões de financiamento dão-se de acordo com uma ordem de preferências: primeiro a firma financia-se com recursos internos, depois recorre ao endividamento externo e somente em última instância recorre à emissão de ações.

Terra (2002) apresenta o efeito esperado sobre o endividamento em cada teoria, de cada variável explicativa utilizada neste estudo: tangibilidade, lucratividade, tamanho e oportunidades de crescimento (Quadro 1).

Quadro 1. Dimensões testadas e o sinal esperado de acordo com a classificação teórica

\begin{tabular}{|l|c|c|}
\hline \multirow{2}{*}{\multicolumn{1}{|c|}{ Dimensões }} & \multicolumn{2}{c|}{ Efeito esperado sobre o endividamento } \\
\cline { 2 - 3 } & Static Tradeoff Theory & Pecking Order Theory \\
\hline Tangibilidade & Positivo & Positivo \\
\hline Lucratividade & Positivo & Negativo \\
\hline Tamanho & Positivo & Negativo \\
\hline Oportunidades de crescimento & Negativo & Positivo \\
\hline
\end{tabular}

Fonte: Terra (2002).

Na estratégia conhecida como static tradeoff, as empresas teriam um nível de endividamento definido, buscando o equilíbrio entre os benefícios e os custos deste endividamento. Toda a vez que a empresa se afastasse do nível definido, seus gestores contrairiam dívida ou emitiriam ações para voltar ao nível de equilíbrio (MORAES e RHODEN, 2005).

A Static Tradeoff Theory considera que o endividamento goza de benefícios tributários que influenciam o valor da firma. O tradeoff nasce, porque a partir de certo nível, a alavancagem passa a gerar custos de transação, devido à maior probabilidade de falência. Como conseqüência, haveria um nível de endividamento ótimo que maximiza o valor da

\footnotetext{
${ }^{5}$ Teoria da existência de um nível ótimo de endividamento.

${ }^{6}$ Teoria de Hierarquia de Fontes.
} 
- Análise dos determinantes do endividamento das empresas de capital aberto do agronegócio brasileiro

empresa, em contraste com a irrelevância da forma de financiamento encontrada no mundo de mercados perfeitos de Miller e Modigliani (SANTANA e TUROLLA, 2002).

A teoria denominada pecking order surgiu na esteira da abordagem de assimetria de informação. Este modelo foi proposto por Myers (1984) e Myers e Majluf (1984), os quais mostraram como a assimetria de informação influencia nas decisões de financiamento das empresas. Estes autores assumiram como pressupostos:

a) a existência de assimetria informacional entre os indivíduos internos e externos à firma, sendo oneroso para os gestores a divulgação inequívoca da informação privilegiada que possuem. Tal assimetria conduz a um problema de seleção adversa na busca de financiamento externo para projetos de investimento.

b) a gerência age sempre no sentido de maximizar a riqueza dos acionistas já existentes na empresa. Assim, na hipótese de financiamento por meio da emissão de ações no mercado, o que importa para o gerente é o valor gerado para os acionistas já existentes no momento da decisão de financiamento.

c) os acionistas são passivos. Desta forma, a gerência da empresa possui o poder discricionário total sobre as decisões de investimento.

d) assume-se um mercado perfeito, sem custos de transação ou de colocação de títulos, e eficiente na forma semi-forte, ou seja, toda informação pública é conhecida pelo mercado. É assumido, também, que o valor das ações da firma é dado pelo valor esperado da mesma, condicionado às informações que o mercado possui.

$\mathrm{Na}$ teoria pecking order, os gestores teriam uma ordem de hierarquia de financiamento para seus investimentos. As empresas primeiro utilizariam recursos internos (retenção de lucros) para financiar seus projetos. Na necessidade de utilização de recursos externos, as empresas preferem contrair dívida e, em último caso, emitir novas ações (MORAES e RHODEN, 2005).

Diferentemente da abordagem de static tradeoff, não há uma meta de endividamento. Este ocorrerá na medida em que apareçam as oportunidades de investimento.

Soares e Kloeckner (2005) fizeram um levantamento dos trabalhos utilizando a pecking order theory e constataram que alguns confirmaram, outros negaram as hipóteses relativas ao modelo, ou apresentaram resultados conflitantes conforme pode-se verificar pelo Quadro 2. 
Quadro 2. Resumo de exemplos de trabalhos que testaram empiricamente o pecking order

\begin{tabular}{|c|c|c|c|}
\hline Autores & Método utilizado & Tipo de pesquisa & Resultado \\
\hline \multicolumn{4}{|c|}{ Estudos no Mercado Internacional } \\
\hline $\begin{array}{l}\text { Amihud, Lev e } \\
\text { Travlos (1990) }\end{array}$ & Múltiplos métodos. & $\begin{array}{c}\text { Teste da influência do } \\
\text { mercado por controle } \\
\text { corporativo nas formas } \\
\text { de financiamento }\end{array}$ & $\begin{array}{c}\text { Consistentes com o } \\
\text { P.O }\end{array}$ \\
\hline $\begin{array}{l}\text { Ghosh e Cai } \\
(1999)\end{array}$ & $\begin{array}{c}\text { Tabelas de } \\
\text { contingências } \\
\end{array}$ & $\begin{array}{c}\text { Teste do P.O. contra } \\
\text { static tradeoff nos EUA }\end{array}$ & $\begin{array}{l}\text { Evidências consistentes } \\
\text { e outras inconsistentes. }\end{array}$ \\
\hline Babu e Jain (1998) & Survey & $\begin{array}{c}\text { Survey de executivos } \\
\text { na Índia }\end{array}$ & $\begin{array}{l}\text { Consistentes com o } \\
\text { P.O. }\end{array}$ \\
\hline $\begin{array}{c}\text { Shyam-Sunder e } \\
\text { Myers (1999) }\end{array}$ & $\begin{array}{l}\text { Regressão, c/ modelo } \\
\text { para déficit de caixa e } \\
\text { estrutura meta de } \\
\text { capital. Simulação }\end{array}$ & $\begin{array}{c}\text { Teste do P.O. contra } \\
\text { static tradeoff nos EUA }\end{array}$ & $\begin{array}{c}\text { Consistentes com o } \\
\text { P.O. }\end{array}$ \\
\hline $\begin{array}{l}\text { Fama e French } \\
\text { (2002) }\end{array}$ & Regressões mútiplas & $\begin{array}{c}\text { Testes das previsões do } \\
\text { P.O. para estrutura de } \\
\text { capital e dividendos } \\
\text { nos EUA }\end{array}$ & $\begin{array}{l}\text { Evidências consistentes } \\
\text { e outras inconsistentes. }\end{array}$ \\
\hline Adedeji (2002) & $\begin{array}{c}\text { Réplica de } \\
\begin{array}{c}\text { Shyam-Sunder e Myers } \\
(2002)\end{array} \\
\end{array}$ & \begin{tabular}{|c} 
Teste do P.O. contra \\
static tradeoff no Reino \\
Unido.
\end{tabular} & $\begin{array}{l}\text { O P.O. não é melhor } \\
\text { do que o static tradeoff }\end{array}$ \\
\hline \begin{tabular}{|c|}
$\begin{array}{c}\text { Titman e Wessels } \\
(1988)\end{array}$ \\
\end{tabular} & Regressão múltipla & $\begin{array}{c}\text { Determinantes da E.C. }{ }^{8} \\
\text { nos EUA }\end{array}$ & $\begin{array}{l}\text { Suporte a algumas } \\
\text { dimensões do P.O. }\end{array}$ \\
\hline $\begin{array}{c}\text { Rajan e Zingales } \\
(1995)\end{array}$ & Regressão múltipla & $\begin{array}{l}\text { tes da E.C. } \\
\text { do G7 }\end{array}$ & $\begin{array}{l}\text { Evidências consistentes } \\
\text { e outras inconsistentes. }\end{array}$ \\
\hline $\begin{array}{l}\text { Terra }(2002 a ; \\
2002 b)\end{array}$ & Regressões em painel & $\begin{array}{l}\text { Determinantes da E.C. } \\
\text { na América Latina }\end{array}$ & $\begin{array}{c}\text { Algumas evidências } \\
\text { consistentes com o P.O. }\end{array}$ \\
\hline \multicolumn{4}{|c|}{ Estudos no mercado brasileiro } \\
\hline Eid Júnior (1996) & Survey & $\begin{array}{c}\text { Survey com executivos } \\
\text { brasileiros }\end{array}$ & $\begin{array}{c}\text { Consistentes com o } \\
\text { P.O. }\end{array}$ \\
\hline $\begin{array}{c}\text { Ferreira e Brasil } \\
(1997)\end{array}$ & $\begin{array}{c}\text { Análise exploratória } \\
\text { univariada }\end{array}$ & Teste do P.O. no Brasil & $\begin{array}{c}\text { Consistentes com o } \\
\text { P.O. }\end{array}$ \\
\hline \begin{tabular}{|c|}
$\begin{array}{c}\text { Santana e Turolla } \\
(2002)\end{array}$ \\
\end{tabular} & \begin{tabular}{|c|} 
Réplica de Shyam- \\
Sunder e Myers (2002)
\end{tabular} & $\begin{array}{l}\text { Teste do P.O. contra } \\
\text { tradeoff no Brasil. }\end{array}$ & Inconclusivos \\
\hline $\begin{array}{c}\text { Medeiros e Daher } \\
(2004)\end{array}$ & $\begin{array}{c}\text { Réplica de Shyam- } \\
\text { Sunder e Myers (2002) }\end{array}$ & $\begin{array}{l}\text { Teste do P.O. contra } \\
\text { tradeoff no Brasil. }\end{array}$ & $\begin{array}{l}\text { Consistentes com o } \\
\text { P.O. na sua forma fraca }\end{array}$ \\
\hline $\begin{array}{l}\text { Gomes e Leal } \\
\quad(2001)\end{array}$ & Regressão múltipla & $\begin{array}{c}\text { Determinantes da E.C. } \\
\text { no Brasil }\end{array}$ & $\begin{array}{c}\text { Elementos consistentes } \\
\text { com o P.O. e com } \\
\text { outras teorias de E.C. }\end{array}$ \\
\hline
\end{tabular}

Fonte: Soares e Kloeckner (2005).

\footnotetext{
7 P.O. = pecking order

${ }^{8}$ E.C $=$ estrutura de capital.
} 
- Análise dos determinantes do endividamento das empresas de capital aberto do agronegócio brasileiro

\subsection{Modelo de Rajan e Zingales (1995)}

Rajan e Zingales (1995) investigaram os determinantes da escolha da estrutura de capital, analisando as decisões das empresas públicas não-financeiras dos maiores países industrializados (EUA, Japão, Alemanha, França, Itália, Reino Unido e Canadá) no período de 1987-1991. Eles partiram do pressuposto da existência de uma estrutura de capital ótima no qual os benefícios e custos do endividamento estariam balanceados.

Discutindo medidas de alavancagem, que é o foco do presente trabalho, estes autores mencionaram que o relevante, para o trabalho deles, é o provável estoque de dívidas relativos ao valor da firma, cuja ampla definição de estoque de dívidas é dada pela razão do total do passivo, excluindo o capital próprio, sobre o total do ativo. E a mais apropriada definição de alavancagem financeira provê da razão das dívidas (de curto e longo prazo) sobre o total do ativo.

O modelo definido por estes autores assumiu a seguinte especificação:

$$
\mathrm{D}_{\mathrm{it}}=\alpha+\beta_{\mathrm{T}} \mathrm{T}_{\mathrm{it}}+\beta_{\mathrm{MVMP}} \mathrm{VMVP}_{\mathrm{it}}+\beta_{\mathrm{LnV}} \operatorname{LnV}_{\mathrm{it}}+\beta_{\mathrm{LUC}} \mathrm{LUC}_{\mathrm{it}}+\varepsilon_{\mathrm{it}}
$$

Em que: $D_{i t}=$ Nível de Endividamento (Alavancagem); $\mathrm{T}_{\mathrm{it}}=$ Tangibilidade dos ativos; $\mathrm{VMVP}_{\text {it }}=$ Índice Valor de Mercado sobre Valor Patrimonial; $\operatorname{LnV}_{i t}=$ Logaritmo Natural das Vendas; e $L C_{i t}=$ Lucratividade. Subscritos $i$ e $t$ representaram a empresa $i$ no momento $t$.

Os autores especificaram a equação (I) de duas formas, inicialmente assumiram a variável dependente como alavancagem contábil, a qual foi especificada como dívida ajustada sobre a dívida ajustada mais o valor contábil do capital próprio ajustado; e posteriormente como alavancagem de mercado, definida como dívida ajustada sobre a dívida ajustada mais o valor de mercado do capital próprio ajustado.

Rajan e Zingales (1995) utilizaram os valores médios para as variáveis independentes e operacionalizaram a equação (I) utilizando o modelo Tobit'.

Os mesmos autores constataram, em nível agregado, que a alavancagem das firmas era razoavelmente similar entre os países do G-7.

\footnotetext{
${ }^{9}$ Segundo Rajan e Zingales (1995), em alguns casos, os ajustamentos geraram valores negativos para a alavancagem. Para eliminar os outliers os autores truncaram a amostra em -1. Por esta razão, utilizaram o modelo Tobit. Os resultados por mínimos quadrados ordinários foram muito similares.
} 
Não consideraram surpreendente que todos os coeficientes para as empresas dos EUA tiveram o mesmo sinal encontrado em estudo prévio de Harris e Raviv (1991) e foram significativos ao nível de 1\%. Verificaram que todos os coeficientes das variáveis tangibilidade, valor de mercado sobre o valor patrimonial, logaritmo natural das vendas e lucratividade apresentaram seus sinais esperados quando a variável dependente foi alavancagem de mercado.

\section{Metodologia}

\subsection{Amostra, coleta de dados e unidades de análise}

Conforme trabalho de Araújo et. al. (2004, p. 215) foram selecionadas todas as empresas listadas na Bovespa que estivessem enquadradas em algum dos três sub-setores do agronegócio brasileiro, a saber: setor de produção agropecuária; setor fornecedor de insumos e fatores de produção; e setor de processamento e distribuição. (...) Esta seleção ampla está de acordo com a Confederação de Agricultura e Pecuária do Brasil, CNA, no que tange à definição do referido setor no País.

Os dados anuais foram extraídos da Economática ${ }^{\circledR}$ durante o período 1999 a 2005. Inicialmente, a amostra era composta por 35 empresas. Entretanto, aquelas cujos dados estavam incompletos foram excluídas da amostra, perfazendo um total de 26 empresas, sendo elas: Alpargatas, Ambev, Aracruz, Avipal, Buettner, Cacique, Coteminas, Embraco, Fertibras, Fosfertil, Guararapes, Klabin, Minupar, Perdigão, Rasip Agro Pastoril, Sadia, Santista Têxtil, Schulz, Souza Cruz, Suzano Papel, Teka, Vicunha Têxtil, Vigor, Votorantim Celulose Papel, Weg e Yara Brasil. Todas as informações monetárias foram corrigidas pelo IPCA de $31 / 12 / 2005$.

\subsection{Caracterização das Variáveis}

Conforme Rajan e Zingales (1995), Kayo e Fama (1997), Daher (2004), Basso, Mendes e Kayo (2004), Soares e Kloeckner (2005), Moraes e Rhoden (2005), Matin et. al. (2005) e Barros, Silveira e Silveira (2006), foram utilizadas, no presente estudo, duas medidas para o endividamento das empresas: endividamento contábil e endividamento de mercado. 
No entanto, conforme sugestão do trabalho de Daher (2004, p. 41) dependendo se a exigibilidade onerosa incluía dívidas de curto e longo prazo ou apenas de longo prazo e se o valor da empresa era dado por seu valor patrimonial ou de mercado gerou-se várias medidas de endividamento.

Obtendo assim, oito ${ }^{10}$ medidas de endividamento que constituirão as variáveis dependentes do estudo:

1) DivTotAL $L_{i t}$ - Dívida total (passivo oneroso ${ }^{11}$ de curto e longo prazos) dividida pelo ativo líquido (ativo total menos passivo de funcionamento ${ }^{12}$ ).

2) DivTotVM $\mathrm{i}_{\mathrm{it}}$ - Dívida total (passivo oneroso de curto e longo prazos) dividida pelo valor de mercado das ações mais o valor total do passivo oneroso.

3) DivTotAT $T_{i t}-$ Dívida total (passivo oneroso de curto e longo prazos) dividida pelo ativo total.

4) DivTotPL $L_{i t}$ - Dívida total (passivo oneroso de curto e longo prazos) dividida pelo valor do patrimônio líquido mais o valor total do passivo oneroso.

5) DivLPAL $L_{\text {it }}$ - Dívida de longo prazo (passivo oneroso de longo prazo) dividida pelo ativo líquido (ativo total menos passivo de funcionamento).

6) DivLPVM $\mathrm{it}_{\mathrm{it}}$ - Dívida de longo prazo (passivo oneroso de longo prazo) dividida pelo valor de mercado das ações mais o valor do passivo oneroso de longo prazo.

7) $\operatorname{DivLPAT}_{\text {it }}$ - Dívida de longo prazo (passivo oneroso de longo prazo) dividida pelo ativo total.

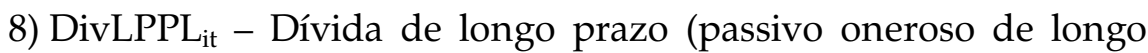
prazo) dividida pelo valor do patrimônio líquido mais o valor do passivo oneroso de longo prazo.

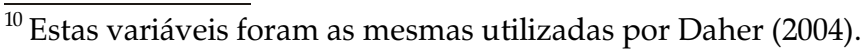

${ }^{11} \mathrm{O}$ passivo oneroso é composto pelas dívidas contraídas pela empresa (montante de capital de terceiros) sobre as qual incidem juros.

${ }^{12}$ Passivo de funcionamento são as contas do balanço necessárias ao funcionamento da empresa e sobre as quais a empresa não paga encargos.
} 
As variáveis independentes foram indicadas por Harris e Raviv (1995) como importantes na determinação do endividamento das empresas e posteriormente testadas por Rajan e Zingales (1995) e Daher (2004). Sendo elas:

\section{A) Tangibilidade dos Ativos}

Conforme Daher (2004, p. 38), "espera-se que empresas que tenham ativos mais tangíveis apresentem maior nível de endividamento. $\mathrm{O}$ motivo é a possibilidade destes ativos serem utilizados como garantia para empréstimos."

Esta variável foi dividida em duas, conforme procedimento adotado por Lemmon e Zender (2002). Na tangibilidade total considerou-se tanto o imobilizado quanto os estoques, pois este último pode ser utilizado como garantia em empréstimos devido à maior liquidez, já para a tangibilidade de longo prazo, apenas o imobilizado.

- $\mathrm{TG}_{i t}$ - tangibilidade dos ativos de curto e longo prazo que corresponde à soma da rubrica 'estoques' com a rubrica 'imobilizado';

- $\mathrm{TGLP}_{\text {it }}$ - tangibilidade dos ativos de longo prazo, onde apenas a rubrica 'imobilizado' é considerada.

B) Índice valor de mercado sobre valor patrimonial

Este índice, utilizado pelos autores Titman e Wessels (1988), Rajan e Zingales (1995), Baker e Wurgler (2002), Korajczyk e Levy (2003), Frank e Goyal (2003a e 2003b) e Daher (2004), é uma proxy para oportunidade de crescimento. Foi extraído do índice Preço/Valor Patrimonial da Ação fornecido pela Economática®.

De acordo com Daher (2004, p. 39), "espera-se que empresas com maiores oportunidades de crescimento tenham um nível de endividamento mais baixo, porque o peso das dívidas pode levá-las a ter que diminuir a velocidade com que esperavam crescer (MYERS, 1977) e também porque estas empresas geram maior percepção de risco, forçando-as a trabalhar com maior volume de capital próprio (RAJAN e ZINGALES, 1995)". Por outro lado, espera-se que firmas com menores oportunidades de crescimento tenham maior endividamento.

- $\mathrm{PVP}_{\mathrm{it}}-$ Valor de Mercado sobre Valor Patrimonial 
C) Logaritmo natural das vendas

O logaritmo natural das vendas é geralmente utilizado como proxy para o tamanho das empresas. (...) O fator tamanho é considerado como um determinante importante da alavancagem. Para Titman e Wessels (1995) e Brailsford et. al. (2002), empresas maiores tendem a ser mais diversificadas e apresentarem menor risco de falência, podendo, portanto, carregar um maior endividamento. Marsh (1982) espera que a proporção entre dívidas de longo prazo e curto prazo seja maior para as empresas maiores. As empresas menores devem ter suas dívidas concentradas no curto prazo. $\mathrm{O}$ maior motivo se dá pelos altos custos de emissão, que torna o mercado financeiro inacessível para as menores. (DAHER, 2004, p. 40).

A variável foi obtida do banco de dados da Economática ${ }^{\circledR}$, tirando-se o logaritmo natural da rubrica "Receita Líquida Operacional", encontrada na DRE.

- $\mathrm{LnV}_{\mathrm{it}}-$ Logaritmo natural das vendas.

\section{D) Lucratividade}

Conforme Rajan e Zingales (1995) a lucratividade é negativamente correlacionada com a alavancagem. De acordo com Daher (2004, p. 41)

Para a STT, quanto maior a lucratividade das empresas, mais elas teriam motivos para recorrerem ao endividamento e com isso tentar diminuir a carga tributária, devido à dedutibilidade dos juros do lucro tributável. Já a POT pressupõe que lucros maiores levam à formação da principal fonte à qual recorrem as empresas para cobrirem seu déficit financeiro: os lucros retidos. Assim, a STT espera uma relação positiva entre a lucratividade e alavancagem, enquanto que a POT espera o oposto.

- Luc $_{i t}-$ Lucratividade (EBITDA/Ativo Total)

Utilizou-se o EBITDA ${ }^{13}$, conforme sugestão dos trabalhos de Rajan e Zingales (1995), Basso, Mendes e Kayo (2004), Soares e Kloeckner (2005), Moraes e Rhoden (2005) e Brito, Batistella e Corrar (2005).

${ }^{13}$ Ebitda: Earnings Before Interest, Taxes, Depreciation and Ammortization (Lucro Antes de Juros, Impostos, Depreciação e Amortização). 
De acordo com o procedimento adotado por Daher (2004), todas as variáveis, não-índices, foram divididas pelo Ativo Total de cada empresa, normalizando a amostra em função do tamanho.

\subsection{Modelo Analítico}

\subsubsection{Regressão com dados em painel}

$\mathrm{Na}$ análise de regressão com dados em painel, a mesma unidade de corte transversal - neste estudo as empresas do agronegócio brasileiro -é acompanhada ao longo do tempo. Em síntese, os dados em painel têm uma dimensão espacial e outra, temporal. Este tipo de análise oferece uma série de vantagens sobre as análises tradicionais de corte transversal e séries temporais, as quais foram listadas por Hsiao $(1985,1986)$, Klevmarken (1989) e Sólon (1989) e citadas por Baltagi (1995, p. 3-5), a saber:

$1^{\circ}$ ) Controle para heterogeneidade individual;

$2^{\circ}$ ) Utilização de dados com maior poder de informação, maior variabilidade, menor colinearidade entre as variáveis, mais graus de liberdade e mais eficiência estatística;

$3^{\circ}$ ) Melhores condições para se estudar as dinâmicas de ajustamento;

$4^{\circ}$ ) Permitem identificar e medir efeitos não detectáveis através de cortes transversais e séries temporais isoladamente;

$5^{\circ}$ ) Permite-se construir e testar modelos com comportamento mais complexo se comparado com os modelos puros de série temporal e de corte transversal;

$6^{\circ}$ ) Os vieses resultantes da agregação de dados são eliminados.

Por outro lado, quando se trabalha com dados em painel, tem-se as seguintes limitações (BALTAGI, 1995):

$\left.1^{\circ}\right)$ Problemas de coleta de dados;

$2^{\circ}$ ) Distorções resultantes de erros de medidas;

$3^{\circ}$ ) Problema de seletividade, resultantes de dados faltantes que geram problemas de painéis não balanceados;

$4^{\circ}$ ) Dimensão de série temporal curta.

Existem três tipos de modelos de dados em painel: o de coeficiente constante, o de efeitos fixos e o de efeitos aleatórios. Estes modelos se 
subdividem em painéis estáticos e dinâmicos, modelos robustos e modelos estruturais de covariância (GREENE, 2003).

O modelo de coeficientes constantes pressupõe que tanto o intercepto quanto as inclinações não variam. Neste caso, nem efeitos inerentes aos objetos pesquisados nem ao passar do tempo teriam qualquer efeito sobre o modelo. Este modelo também é chamado de pooled regression (Daher, 2004).

$\mathrm{Na}$ abordagem de efeitos fixos, pode-se considerar as seguintes possibilidades:

a) os coeficientes angulares são constantes, mas o intercepto varia entre as empresas;

b) os coeficientes angulares são constantes, mas o intercepto varia entre empresas e ao longo do tempo;

c) os coeficientes (intercepto e angulares) variam entre as empresas;

d) o intercepto e os coeficientes angulares variam entre empresas e ao longo do tempo (GUJARATI, 2006).

O modelo de efeitos fixos é adequado a situações em que o intercepto de cada empresa pode estar correlacionado com um ou mais regressores. A desvantagem do modelo de efeitos fixos está na necessidade de se incluir um número muito grande de variáveis dummies. Este número excessivo de variáveis leva à perda de uma elevada quantidade de graus de liberdade na estimação do modelo. Além disso, este tipo de modelo pode apresentar multicolinearidade.

No modelo de efeitos aleatórios, supõe-se que o intercepto de uma unidade individual é uma extração aleatória de uma população muito maior com um valor médio constante. A estimação de efeitos aleatórios pode ser feita por meio da técnica Generalized Least Squares (GLS) ou o Feasible Generalized Least Squares (FGLS), que dependerá das propriedades do termo estocástico.

Uma vantagem do modelo de efeitos aleatórios em relação ao modelo de efeitos fixos é que é econômico em graus de liberdade, já que não tem-se que estimar $\mathrm{N}$ interceptos individuais. Só é necessário estimar o valor médio do intercepto e sua variância.

A questão a ser feita é qual estimação deve ser utilizada, efeitos fixos ou aleatórios? $\mathrm{O}$ teste de Hausman pode ser empregado para se tomar esta decisão. 
O presente trabalho utilizou o modelo de dados em painel estático devido à opção de se utilizar o mesmo modelo testado por Rajan e Zingales (1995), no qual o endividamento passado não foi considerado entre os regressores. Estimou-se equações com efeitos fixos e outras com aleatórios, em conformidade com o teste de Hausman.

A estrutura básica do modelo de regressão em painel, de acordo com Rajan e Zingales (1995), utilizada nesta pesquisa, é dada por:

$$
D_{i t}=\alpha+\beta_{T} T_{i t}+\beta_{M V M P} V M V P_{i t}+\beta_{L n V} L n V_{i t}+\beta_{L U C} L U C_{i t}+\varepsilon_{i t}
$$

As variáveis da equação (I) já foram descritas no tópico 3.2, assumindo que $\mathrm{D}$, assumirá oito alternativas de índices de endividamento. Os seguintes testes foram realizados, de forma a garantir a robustez dos resultados empíricos ${ }^{14}$ : Teste de Breusch e Pagan e Teste de Hausman.

\subsubsection{Teste de Breusch e Pagan -}

Estatística do Multiplicador de Lagrange (LM)

Conforme Daher (2004), o teste de Breusch e Pagan é baseado na correlação dos resíduos e tem distribuição de $\chi^{2}$. Esta estatística auxilia na definição do uso ou não de modelo com efeitos (fixos ou aleatórios). Caso os valores obtidos para a estatística LM sejam superiores ao valor crítico, rejeita-se a hipótese nula de que o modelo sem efeitos ${ }^{15}$ é mais adequado. Este teste foi operacionalizado no software Stata Satistical Software, versão 9.1.

\footnotetext{
${ }^{14}$ Conforme Daher $(2004$, p. 52), “testes de raízes unitárias são comumente utilizados para se testar a estacionaridade de séries temporais, evitando assim o problema de regressões espúrias. Criados inicialmente para séries temporais simples, vários métodos foram desenvolvidos recentemente para o uso em séries em panel data (IM, PESARAN e SHIN, 2003; MADDALA e WU, 1999; BANERJEE, 1999). No entanto, Baltagi (2001, p.233-236) mostra que tais testes somente se justificam para macro-painéis (i.e.,quando as séries temporais e os cortes transversais tendem ao infinito). No caso de micro-painéis (onde as séries temporais são pequenas enquanto os cortes transversais tendem ao infinito), testes para raízes unitárias não se fazem necessários nem se justificam. Os dados do presente trabalho são um caso típico de micro-painel. Seguindo Batalgi (2001), não foram realizados testes para raízes unitárias."

${ }^{15}$ Conforme Daher (2004), o modelo sem efeito é o mais simples, como uma pooled regression com mínimos quadrados ordinários sem levar em conta nenhum tipo de efeito individual ou temporal, fixo ou aleatório.
} 


\subsubsection{Teste de Wu-Hausman}

De acordo com Johnston e DiNardo (2001, p. 12), deduz-se dois estimadores que têm diferentes propriedades, considerando se $\alpha_{\mathrm{i}}$ e os regressores estão correlacionados ou não. Especificamente:

1) Se os efeitos não estão correlacionados com as variáveis explicativas, o estimador de efeitos aleatórios (RE) é consistente e eficiente. O estimador de efeitos fixos (FE) é consistente, mas não é eficiente.

2) Se os efeitos estão correlacionados com as variáveis explicativas, o estimador de efeitos fixos é consistente e eficiente, mas, agora, o estimador de efeitos aleatórios é não consistente.

Esta diferença dá origem a um caso típico do teste de Hausman que é definido como:

$$
\mathrm{H}=\left(\hat{\beta}_{\mathrm{RE}}-\hat{\beta}_{\mathrm{FE}}\right)\left(\Sigma_{\mathrm{FE}}-\Sigma_{\mathrm{RE}}\right)^{-1}\left(\hat{\beta}_{\mathrm{RE}}-\hat{\beta}_{\mathrm{FE}}\right) \sim \chi^{2}(\mathrm{k})
$$

A estatística de teste terá, sob a hipótese nula de que o estimador de efeitos aleatórios é correto, uma distribuição $\chi^{2}(\mathrm{k})$.

Cabe ressaltar que um resultado possível do teste, que não é pouco comum nas aplicações, é que os dois estimadores não são significativamente diferentes um do outro. Isto pode indicar, simplesmente, que não há variação suficiente na alteração de $X$ para proporcionar resultados suficientemente precisos que permitam a distinção entre os dois conjuntos de estimativas. Este teste foi operacionalizado no software Limdep, versão 8.0.

\section{Resultados e Discussão}

\subsection{Determinantes da alavancagem das empresas do agronegócio brasileiro}

Inicialmente, testou-se se os modelos de regressão, considerando cada uma das variáveis dependentes (dívidas totais, dívidas de longo prazo, relacionadas com o valor contábil e com o valor de mercado), deveriam ser estimados utilizando modelos com efeitos (fixos ou aleatórios) ou não. Com base nos resultados obtidos pelo teste do multiplicador de Lagrange, os modelos com as seguintes variáveis dependentes: dívida total em relação ao ativo líquido, dívida total em relação ao patrimônio líquido e 
dívida de longo prazo em relação ao ativo líquido foram mais adequadas para modelos sem efeitos (Tabela 1). Desta forma, estes modelos foram eliminados para o estudo de dados em painel.

Tabela 1. Teste LM de Breusch Pagan ${ }^{16}$ para as empresas do agronegócio brasileiro no período de 1999 a 2005

\begin{tabular}{|c|c|c|c|}
\hline Modelos estimados por RE & $\mathbf{L M}^{17}$ & Valor $\mathbf{P}$ & $\begin{array}{c}\text { Rejeita (R) ou } \\
\text { Não Rejeita (N/R) }\end{array}$ \\
\hline Divtotal $=\mathrm{f}(\operatorname{tg}$ pvp lnv luc $)$ & 0,73 & 0,3913 & $\mathrm{~N} / \mathrm{R}$ \\
\hline Divtotal $=\mathrm{f}(\operatorname{tgl} \mathrm{p} p v p \operatorname{lnv}$ luc $)$ & 0,66 & 0,4173 & $\mathrm{~N} / \mathrm{R}$ \\
\hline Divtotvm $=\mathrm{f}(\operatorname{tg}$ pvp lnv luc $)$ & 157,61 & 0,0000 & $\mathrm{R}$ \\
\hline Divtotvm $=\mathrm{f}(\operatorname{tglp} p v p \operatorname{lnv} l u c)$ & 164,59 & 0,0000 & $\mathrm{R}$ \\
\hline Divtotat $=\mathrm{f}(\operatorname{tg} \mathrm{pvp} \operatorname{lnv} \mathrm{luc})$ & 160,92 & 0,0000 & $\mathrm{R}$ \\
\hline Divtotat $=\mathrm{f}(\operatorname{tglp}$ pvp lnv luc $)$ & 159,16 & 0,0000 & $\mathrm{R}$ \\
\hline Divtotpl $=\mathrm{f}(\operatorname{tg}$ pvp lnv luc $)$ & 0,90 & 0,3440 & $\mathrm{~N} / \mathrm{R}$ \\
\hline Divtotpl $=\mathrm{f}(\operatorname{tgl} \mathrm{p}$ pvp lnv luc $)$ & 1,20 & 0,2739 & $\mathrm{~N} / \mathrm{R}$ \\
\hline Divlpal $=\mathrm{f}(\mathrm{tg}$ pvp lnv luc $)$ & 0,56 & 0,4524 & $\mathrm{~N} / \mathrm{R}$ \\
\hline Divlpal $=\mathrm{f}(\operatorname{tglp}$ pvp lnv luc $)$ & 0,63 & 0,4268 & $\mathrm{~N} / \mathrm{R}$ \\
\hline Divlpvm $=f(\operatorname{tg}$ pvp lnv luc $)$ & 169,79 & 0,0000 & $\mathrm{R}$ \\
\hline Divlpvm $=f(\operatorname{tgl} p$ pvp lnv luc $)$ & 172,55 & 0,0000 & $\mathrm{R}$ \\
\hline Divlpat $=\mathrm{f}(\mathrm{tg}$ pvp $\operatorname{lnv}$ luc $)$ & 118,48 & 0,0000 & $\mathrm{R}$ \\
\hline Divlpat $=\mathrm{f}($ tglp $\mathrm{pvp} \operatorname{lnv}$ luc $)$ & 96,74 & 0,0000 & $\mathrm{R}$ \\
\hline Divlppl = f(tg pvp lnv luc $)$ & 21,90 & 0,0000 & $\mathrm{R}$ \\
\hline Divlppl $=\mathrm{f}(\operatorname{tglp}$ pvp lnv luc) & 19,45 & 0,0000 & $\mathrm{R}$ \\
\hline
\end{tabular}

Fonte: Dados da Pesquisa.

O segundo passo consistiu em avaliar, exceto os modelos excluídos pelo teste do multiplicador de Lagrange, se seria adequado trabalhar com efeitos fixos ou efeitos aleatórios. As informações da Tabela 2 sinalizam, de acordo com o teste de Hausman, quais modelos deveriam ser operacionalizados utilizando efeitos fixos e quais, efeitos aleatórios.

\footnotetext{
${ }^{16} \mathrm{H}_{0}=$ Modelo sem efeitos é mais adequado

${ }^{17} \mathrm{LM}=$ multiplicador de Lagrange. Conforme texto do software Limdep "High values of LM favor FEM/REM over CR model"
} 
110 - Análise dos determinantes do endividamento das empresas de capital aberto do agronegócio brasileiro

Tabela 2. Teste de Hausman ${ }^{18}$ para as empresas do agronegócio brasileiro no período de 1999 a 2005

\begin{tabular}{lcccc}
\hline Modelos estimados por RE & $\mathbf{H}^{19}$ & Valor P & $\begin{array}{c}\text { Rejeita (R) Não } \\
\text { Rejeita (N/R) }\end{array}$ & $\begin{array}{c}\text { Usar RE } \\
\text { ou FE }\end{array}$ \\
\hline Divtotvm = f(tg pvp lnv luc) & 8,97 & 0,061821 & $\mathrm{~N} / \mathrm{R}$ & $\mathrm{RE}$ \\
Divtotvm = f( tglp pvp lnv luc) & 4,73 & 0,316243 & $\mathrm{~N} / \mathrm{R}$ & $\mathrm{RE}$ \\
Divtotat $=\mathrm{f}$ (tg pvp lnv luc) & 18,91 & 0,000820 & $\mathrm{R}$ & $\mathrm{FE}$ \\
Divtotat = f(tglp pvp lnv luc) & 13,94 & 0,007489 & $\mathrm{R}$ & $\mathrm{FE}$ \\
Divlpvm = f( tg pvp lnv luc) & 3,51 & 0,476545 & $\mathrm{~N} / \mathrm{R}$ & $\mathrm{RE}$ \\
Divlpvm = f( tglp pvp lnv luc) & 2,03 & 0,729886 & $\mathrm{~N} / \mathrm{R}$ & $\mathrm{RE}$ \\
Divlpat $=\mathrm{f}($ tg pvp lnv luc) & 10,62 & 0,031162 & $\mathrm{R}$ & $\mathrm{FE}$ \\
Divlpat $=\mathrm{f}($ tglp pvp lnv luc) & 8,21 & 0,084057 & $\mathrm{~N} / \mathrm{R}$ & $\mathrm{RE}$ \\
Divlppl = f( tg pvp lnv luc) & 21,69 & 0,000231 & $\mathrm{R}$ & $\mathrm{FE}$ \\
Divlppl =f( tglp pvp lnv luc) & 22,75 & 0,000142 & $\mathrm{R}$ & $\mathrm{FE}$ \\
\hline
\end{tabular}

Fonte: Dados da Pesquisa. (RE = Efeito aleatório; FE = Efeito Fixo)

Nota-se que o $\mathrm{R}^{2}$ para os modelos de efeitos fixos, tanto considerando a tangibilidade total ${ }^{21}$, quanto tangibilidade de longo prazo, foram muito baixos, além de poucas variáveis independentes estatisticamente significativas (Tabela 3). Neste caso, denota-se a não aplicabilidade do modelo de efeitos fixos a amostra de empresas do agronegócio, apesar das indicações do teste de Hausman. Este resultado justifica-se em função das unidades cross-section terem sido extrações aleatórias de uma população maior, neste sentido, conforme Gujarati (2006), o modelo de efeitos aleatórios passa a ser mais adequado para o estudo. Desta forma, assume-se que as 26 empresas têm um valor médio comum para o intercepto e que as diferenças individuais no intercepto de cada empresa se refletem no termo de erro.

Neste sentido, a escolha do modelo de efeitos aleatório foi também conseqüência dos dados do presente estudo. Esta abordagem é compatível com Heij et. al. (2004, p. 274) que menciona "we are not primarily interested in testing a particular theory but in using data to get a better

\footnotetext{
${ }^{18} \mathrm{H}_{0}=\mathrm{O}$ efeito aleatório é correto

${ }^{19}$ Conforme texto do software Limdep "High (low) values of H favor FEM (REM)".

${ }^{20}$ Considerou-se o nível de significância de $5 \%$.

${ }^{21}$ A tangibilidade total e de longo prazo apresentaram alta correlação, de modo que estas variáveis não foram estimadas no mesmo modelo. Os resultados das matrizes correlação podem ser disponibilizados pelos autores a quem possa interessar.
} 
understanding of an observed phenomenon of interest. The major role of rests in then to find out whether the chosen model is able to represent the main characteristics of interest of the data".

Tabela 3. Modelos Estimados com base no modelo de Rajan e Zingales (1995) utilizando efeitos fixos

\begin{tabular}{|c|c|c|c|c|c|c|}
\hline Variáveis & Divtotal & Divlppl & Divlpat & Variáveis & Divtotal & Divlppl \\
\hline TG & $\begin{array}{l}0,1511 \mathrm{~ns} \\
(1,1280)\end{array}$ & $\begin{array}{l}0,1539 \mathrm{~ns} \\
(0,4801)\end{array}$ & $\begin{array}{l}0,0640 \mathrm{~ns} \\
(0,1209)\end{array}$ & TGLP & $\begin{array}{l}-0,2650 \mathrm{~ns} \\
(1,2248)\end{array}$ & $\begin{array}{l}-0,2153 \mathrm{~ns} \\
(0,5213)\end{array}$ \\
\hline PVP & $\begin{array}{l}-0,0047 \mathrm{~ns} \\
(0,01283)\end{array}$ & $\begin{array}{l}0,00344 \mathrm{~ns} \\
(0,0054)\end{array}$ & $\begin{array}{l}-0,0015 \mathrm{~ns} \\
(0,0013)\end{array}$ & PVP & $\begin{array}{l}-0,0049 \mathrm{~ns} \\
(0,0128)\end{array}$ & $\begin{array}{l}0,0032 \mathrm{~ns} \\
(0,0054)\end{array}$ \\
\hline LnV & $\begin{array}{l}0,56322^{* *} \\
(0,2341)\end{array}$ & $\begin{array}{l}0,4424^{*} \\
(0,0996)\end{array}$ & $\begin{array}{l}-, 05777^{* *} \\
(0,0251)\end{array}$ & LnV & $\begin{array}{l}0,5248^{* *} \\
(0,2619)\end{array}$ & $\begin{array}{l}0,4093^{*} \\
(0,1114)\end{array}$ \\
\hline Luc & $\begin{array}{l}-4,0135^{*} \\
(1,0168)\end{array}$ & $\begin{array}{l}0,6933 \mathrm{~ns} \\
(0,4328)\end{array}$ & $\begin{array}{l}-, 01641 \mathrm{~ns} \\
(0,1090)\end{array}$ & Luc & $\begin{array}{l}-4,0401 \text { * } \\
(1,0218)\end{array}$ & $\begin{array}{l}0,6709 \mathrm{~ns} \\
(0,4349)\end{array}$ \\
\hline Const & $\begin{array}{l}-3,13621^{* * *} \\
(1,8744)\end{array}$ & $\begin{array}{l}-3,0404^{*} \\
(0,7978)\end{array}$ & $\begin{array}{l}0,5303^{*} \\
(0,2010)\end{array}$ & Const & $\begin{array}{l}-2,6711 \mathrm{~ns} \\
(2,1175)\end{array}$ & $\begin{array}{l}-2,6322 * \\
(0,9012)\end{array}$ \\
\hline R2 & 0,0439 & 0,0238 & 0,0259 & R2 & 0,0472 & 0,0256 \\
\hline $\mathbf{N}^{\circ}$ obs. & 175 & 175 & 175 & $\mathbf{N}^{\circ}$ obs. & 175 & 175 \\
\hline $\mathbf{N}^{\circ}$ grupos & 26 & 26 & 26 & $\mathbf{N}^{\circ}$ grupos & 26 & 26 \\
\hline
\end{tabular}

Dentre as medidas de nível de endividamento utilizadas para modelos de efeitos aleatórios, que foram estimados pelo método de mínimos quadrados generalizados, apenas a variável dependente dívidas de longo prazo a valor de mercado apresentou todas as variáveis estatisticamente significativas (Tabela 4). Os demais modelos, por não apresentarem a mesma validação estatística, foram descartados como instrumento de análise.

Consequentemente, pode-se constatar que dentre os vários indicadores testados como variável dependente, apenas a DivLPVM foi o mais representativo para o estudo da estrutura de capital das empresas do agronegócio brasileiras listadas na Bovespa, no período de 1999 a 2005 (Tabela 4). 
112 - Análise dos determinantes do endividamento das empresas de capital aberto do agronegócio brasileiro

Tabela 4. Modelos Estimados com base no modelo de Rajan e Zingales (1995) utilizando efeitos aleatórios

\begin{tabular}{|c|c|c|c|c|c|c|}
\hline Variáveis & Divtotvm & Divlpvm & Variáveis & Divtotvm & Divlpvm & Divlpat \\
\hline TG & $\begin{array}{l}0,07478 \mathrm{~ns} \\
(0,19443)\end{array}$ & $\begin{array}{l}0,31023^{* * *} \\
(0,18056)\end{array}$ & TGLP & $\begin{array}{l}0,51614^{*} \\
(0,18922)\end{array}$ & $\begin{array}{l}0,62290^{*} \\
(0,17377)\end{array}$ & $\begin{array}{l}0,36248^{*} \\
(0,09094)\end{array}$ \\
\hline PVP & $\begin{array}{l}-0,00231 \mathrm{~ns} \\
(0,00245)\end{array}$ & $\begin{array}{l}-0,00384 * * * \\
(0,00230)\end{array}$ & PVP & $\begin{array}{l}-0,00146 \mathrm{~ns} \\
(0,00241)\end{array}$ & $\begin{array}{l}-0,00299 \mathrm{~ns} \\
(0,00225)\end{array}$ & $\begin{array}{l}-0,00081 \mathrm{~ns} \\
(0,00129)\end{array}$ \\
\hline LnV & $\begin{array}{l}-0,10203 * \\
(0,02992)\end{array}$ & $\begin{array}{l}-0,05455^{* *} \\
(0,02724)\end{array}$ & LnV & $\begin{array}{l}-0,07378^{* *} \\
(0,03078)\end{array}$ & $\begin{array}{l}-0,03051 \mathrm{~ns} \\
(0,02778)\end{array}$ & $\begin{array}{l}0,01616 \mathrm{~ns} \\
(0,01330)\end{array}$ \\
\hline Luc & $\begin{array}{l}-0,56610^{*} \\
(0,19129)\end{array}$ & $\begin{array}{l}-0,41734^{* *} \\
(0,17946)\end{array}$ & Luc & $\begin{array}{l}-0,48015^{* *} \\
(0,18935)\end{array}$ & $\begin{array}{l}-0,32703 * * * \\
(0,17649)\end{array}$ & $\begin{array}{l}-0,00477 \mathrm{~ns} \\
(0,10107)\end{array}$ \\
\hline Const & $\begin{array}{l}1,19823^{*} \\
(0,26042)\end{array}$ & $\begin{array}{l}0,57889 * * \\
(0,23835)\end{array}$ & Const & $\begin{array}{l}0,81493^{*} \\
(0,25806)\end{array}$ & $\begin{array}{l}0,30935 * * \\
(0,23324)\end{array}$ & $\begin{array}{l}-0,10657 \mathrm{~ns} \\
(0,11267)\end{array}$ \\
\hline $\mathbf{R} 2$ & 0,1783 & 0,1597 & R2 & 0,2157 & 0,1984 & 0,1459 \\
\hline $\mathbf{N}^{\circ}$ obs. & 175 & 175 & $\mathbf{N}^{\circ}$ obs. & 175 & 175 & 175 \\
\hline $\mathbf{N}^{\circ}$ grupos & 26 & 26 & $\mathbf{N}^{\circ}$ grupos & 26 & 26 & 26 \\
\hline
\end{tabular}

$\mathrm{O}$ indicador de tangibilidade total dos ativos apresentou sinal positivo, confirmando que ativos mais tangíveis proporcionam a possibilidade das empresas do agronegócio possuírem um maior nível de endividamento, pois os mesmos podem ser utilizados como garantia para empréstimos (Tabela 4). Esta constatação é apresentada por Daher (2004) e também confirmada pelos trabalhos de: Rajan e Zingales (1995), Gomes e Leal (2001), Brito e Lima (2003) e de Terra (2002).

A variável índice valor de mercado sobre valor patrimonial, uma proxy para oportunidade de crescimento das empresas, apresentou sinal negativo (Tabela 4). A relação inversa entre endividamento e oportunidade de crescimento é compatível com os trabalhos de Gomes e Leal (2001) e Moraes e Rhoden (2005).

De acordo com Soares e Kloeckner (2005), em empresas onde o controle é definido, as oportunidades de crescimento não são positivamente relacionadas ao endividamento. Conforme texto de Daher (2004), níveis elevados de endividamento poderiam comprometer o crescimento futuro esperado da empresa.

A teoria dos custos de agência considera que as empresas em crescimento possuem maior flexibilidade para escolher seus investimentos e, por isso, têm custos de agência também maiores. Além disso, empresas com elevadas taxas de crescimento possuem alto custo de 
falência, pois parte substancial do seu valor está atrelada a expectativas futuras de lucro e não a ativos que possam ser liquidados em caso de dificuldades financeiras. Esses argumentos indicam que as empresas em crescimento deveriam ser menos endividadas, ou seja, há uma relação negativa entre crescimento e endividamento (Brito, Batistella e Corrar, 2005 , p. 9). Entretanto, estes autores não constataram esta hipótese em seu trabalho.

Segundo Fama e French (2002), na teoria POT, há duas possibilidades de sinal para a variável PVP, a versão complexa em que empresas com grandes oportunidades de crescimento tenderiam a manter seu nível de endividamento baixo de forma a não prejudicar sua capacidade de obtenção de crédito junto ao mercado financeiro, gerando, assim, uma relação inversa entre endividamento e crescimento; a versão simples da POT, o crescimento requer investimento que são feitos normalmente com a contração de novas dívidas, neste caso, relação direta.

O logaritmo natural das vendas foi utilizado como proxy para o tamanho das empresas do agronegócio brasileiro listadas na Bovespa e apresentou uma relação inversa com o endividamento (Tabela 4). $\mathrm{O}$ resultado encontrado nega a premissa de que empresas de maior porte tendem a ter maior nível de endividamento, visto que estas têm condições de resolver os problemas de assimetria de informação entre credores e devedores com menores custos, e pagam proporcionalmente custos mais baixos na captação externa de recursos. Além disso, empresas maiores possuírem menor volatilidade em seus fluxos de caixa, o que lhes permite um maior nível de endividamento (FAMA e FRENCH, 2002). Adicionalmente, uma característica do mercado de crédito brasileiro é que as grandes empresas têm maior acesso ao mercado de dívidas de longo prazo do que as pequenas empresas, sobretudo por meio de bancos de desenvolvimento.

Todavia, esta relação inversa entre endividamento e tamanho foi também detectada no trabalho de Gomes e Leal (2001). De acordo com Basso, Mendes e Kayo (2004), o efeito do tamanho na alavancagem é ambíguo. Empresas maiores tendem a serem mais diversificadas e falham menos freqüentemente. Assim, o tamanho pode ser considerado como uma proxy inversa para a probabilidade de falência. Nesta interpretação, o tamanho apresenta um impacto positivo na oferta de dívida. Por outro lado, uma segunda corrente afirma que o tamanho é uma proxy para a 
114 - Análise dos determinantes do endividamento das empresas de capital aberto do agronegócio brasileiro

informação que os investidores externos possuem, o que deveria aumentar a preferência por ações, relativamente ao endividamento.

Frank e Goyal (2003a) comentaram que a relação entre tamanho e endividamento poderia ser negativa, já que, quanto maior a empresa, maiores suas instalações e mais sujeita aos efeitos da seleção adversa preconizada por Myers e Majluf (1984), sendo que, caso esta variável esteja mais correlacionada com o lucro do que com o tamanho, a relação é definitivamente negativa. Esta opinião é corroborada por Harris e Raviv (1991).

Com base na matriz de correlação entre o endividamento de longo prazo a valor de mercado e as variáveis tamanho $(\mathrm{LnV})$ e lucratividade (Luc), contata-se que a variável DivLPVM está mais correlacionada com a lucratividade $(-0,35)$ do que com o tamanho $(-0,25)$, confirmando, assim, as afirmações de Myers e Majluf (1984) e Harris e Raviv (1991).

Segundo Brown, Finn e Hillegeist (2001) apud Lanzana (2004), a assimetria informacional surge quando a companhia possui informação de relevância em termos de valor, que ainda não foi divulgada ao público, porém, pode ser obtida de forma privada por alguns investidores. Até que esta informação esteja disponível ou incorporada no preço das ações, cria-se um problema de seleção adversa impondo risco informacional aos participantes de mercado não informados. Dado que o lucro do investidor informado é igual à perda do investidor não informado, este tenderá a se proteger contra o risco informacional, demandando maiores retornos ex-ante. Assim, ao permitir esta transferência de riqueza entre os investidores no mercado secundário, a assimetria informacional faz com que o custo de capital da empresa aumente ex-ante quando da emissão de ações ou títulos de dívida no mercado primário.

Por último, a variável lucratividade apresentou relação inversa com o endividamento de mercado de longo prazo. Esta relação está em conformidade com o trabalho de Rajan e Zingales (1995), Terra (2002), Soares e Kloeckner (2005), Moraes e Rhoden (2005).

$\mathrm{O}$ relacionamento negativo entre lucratividade e endividamento possui consistência teórica com o modelo de Myers e Majluf (1984), primeiro porque os recursos internos são a primeira fonte de financiamento na hierarquia preferencial do pecking order e, segundo, porque empresas controladas tenderiam a evitar a monitoração dos credores e a diminuição do nível de fluxos de caixa disponíveis decorrentes do endividamento. 
De acordo com a pecking order theory, a melhor opção de financiamento de que dispõe a empresa são os lucros retidos. Este tipo de recurso não produz nenhum tipo de informação assimétrica ao mercado e pode ser utilizado para novos projetos. A assimetria de informações causadas pela emissão de ações ou títulos mais complexos que requeiram uma maior comunicação com o mercado é a base da POT. É exatamente para fugir do prêmio de seleção adversa que esta assimetria de informações acarreta, levando muitas vezes as empresas a deixarem passar oportunidades com VPL positivo, que as empresas recorrem ao autofinanciamento como sua principal fonte de recursos (MYERS, 1984). Este prêmio implica numa taxa de retorno mais elevada que será exigida por um investidor externo pelo fato de ele não possuir o mesmo nível de informação que os gestores da empresa. A relação entre estas duas variáveis deve ser, portanto, negativa.

A conclusão a que se chega é que a lucratividade afasta as empresas do endividamento, ao invés de aproximá-las dele, exatamente como prevê a POT.

Com relação ao modelo ajustado, pode-se afirmar, com base no $\mathrm{R}^{2}$, que as variáveis independentes explicaram $15,97 \%$ do endividamento de mercado de longo prazo. Apesar de ser um percentual não alto, os resultados foram compatíveis com vários estudos citados no presente artigo.

De modo geral, pode-se concluir que o endividamento de mercado de longo prazo está aproximadamente mais compatível com a teoria pecking order, desenvolvido por Myers e Majluf (1984). Entretanto, os resultados estimados, não permitiram resultados conclusivos em função da variável oportunidade de crescimento (Quadro 3).

Ainda a esse respeito, a constatação de Fama e French (2002) de que a oportunidade de crescimento na versão complexa da POT assume o sinal negativo (vide Quadro 3), permite inferir, de acordo com os resultados obtidos, que as empresas se financiariam primeiramente utilizando lucros retidos para, em seguida, recorrer ao endividamento e somente em último caso à uma nova emissão de ações. Esta decisão é conseqüência direta da idéia de que novas emissões proporcionam uma sinalização negativa aos agentes no mercado quanto ao valor da empresa. 
116 - Análise dos determinantes do endividamento das empresas de capital aberto do agronegócio brasileiro

Quadro 3: Dimensões testadas, sinal esperado e resultados obtidos para o modelo de endividamento de mercado de longo prazo das empresas do agronegócio brasileiro, no período de 1999 a 2005

\begin{tabular}{|l|c|c|c|}
\hline & \multicolumn{2}{|c|}{ Efeito sobre o endividamento } & \\
\hline Dimensões & $\begin{array}{c}\text { Sinais esperados } \\
\text { por Terra (2002) } \\
\text { para a POT. }\end{array}$ & $\begin{array}{c}\text { Sinais obtidos no } \\
\text { modelo estimado. }\end{array}$ & Observação \\
\hline Tangibilidade & + & + & \\
\hline $\begin{array}{l}\text { Oportunidade } \\
\text { de crescimento }\end{array}$ & + & - & $\begin{array}{c}\text { Conforme Fama e French } \\
\text { (2002), a POT, na versão } \\
\text { complexa assume sinal } \\
\text { negativo neste caso. }\end{array}$ \\
\hline Tamanho & - & - & \\
\hline Lucratividade & - & - & \\
\hline
\end{tabular}

Fonte: Dados da pesquisa.

Daher (2004, p.81) afirma que "mesmo que houvesse um nível-meta de endividamento a ser alcançado as características econômicas do país se tornam um obstáculo bastante forte para o atingimento desta meta. Mais uma vez, a POT se sobreporia à STT".

Adicionalmente, para o mesmo autor, a taxa de juros brasileira, quer de curto quer de longo prazo, é bastante alta em termos reais. Aliada com a restrição de crédito, no qual os bancos têm como principal opção a compra de títulos do governo, há pouca oferta de créditos privados e os recursos de longo prazo são provenientes basicamente do BNDES, desta forma, tem-se uma situação extremamente favorável para a supremacia da POT.

\section{Conclusão}

Neste estudo, constatou-se que as variáveis apontadas por Rajan e Zingales (1995) como relevantes na determinação do endividamento tais como: tangibilidade dos ativos, oportunidade de crescimento, tamanho e lucratividade, também foram representativas para explicar o endividamento das empresas do agronegócio listadas na Bovespa, no período de 1999 a 2005.

Dentre os oito tipos de índices de endividamento testados neste estudo, o que foi mais representativo para explicar a estrutura de capital 
das empresas do agronegócio brasileiras listadas na Bovespa foi o endividamento de mercado de longo prazo.

No modelo de regressão com dados em painel, a variável tangibilidade indicou relação positiva com o endividamento de mercado de longo prazo; já para as variáveis oportunidade de crescimento, tamanho e lucratividade, as relações foram inversas em relação ao endividamento. Este resultado aproxima-se dos resultados propostos pela pecking order theory. De acordo com Terra (2002), a oportunidade de crescimento deveria ter apresentado sinal positivo para caracterizar a teoria da hierarquia de fontes. Entretanto, se assumirmos a posição de Fama e French (2002) da versão complexa da pecking order theory, a oportunidade de crescimento assume relação inversa com a alavancagem. Assim, pode-se afirmar que os resultados encontrados estão consistentes com a pecking order theory. Ou seja, pode-se afirmar que as empresas do agronegócio brasileiro se financiariam primeiramente por meio de recursos internos recorrendo, em seguida, ao endividamento e, somente em último caso, à emissão de ações.

A principal contribuição do presente trabalho foi a aplicação da análise de estrutura de capital às empresas do agronegócio brasileiro, setor de extrema relevância para a economia nacional. Para trabalhos futuros, sugere-se adotar outros modelos para análise da estrutura de capital das empresas do agronegócio.

\section{Referências Bibliográficas}

ARAÚJO, D. L.; BRESSAN, A. A.; BERTUCCI, L. A.; LAMOUNIER, W. M. O risco de mercado do agronegócio brasileiro: Uma análise comparativa entre os modelos CAPM e GARCH-M. Revista Eletrônica de Gestão Organizacional. Vol. 2, n. 3, Setembro/Dezembro, 2004. Disponível em: $<$ www.gestaoorg.dca.ufpe.br>. Data de acesso: 18/09/2006.

ASSAF NETO, A. Finanças corporativas e valor. São Paulo: Atlas, 2003.

BAKER, M.; WURGLER, J. Market Timing and Capital Structure. The Journal of Finance, Vol. 57, Issue 1 p. 1-32 Feb. 2002. Disponível em: <http://www.tbmc.com.tw/tbmc2/Compustat/pdf/Market\%20Timing\% 20and $\% 20$ Capital $\% 20$ Structure.pdf\# search $=\% 22$ BAKER $\% 2$ C $\% 20 \mathrm{M} . \% 3$ B\%20WURGLER\%2C\%20J\%20\%22Market\%20Timing\%20and\%20Capit al\%20Structure $\% 22 \% 22>$. Data de acesso: 18/09/2006. 
118 - Análise dos determinantes do endividamento das empresas de capital aberto do agronegócio brasileiro

BALTAGI, B. H. Econometric Analysis of Panel Data. New York: John Wiley \& Sons. 1995.

BARROS, L. A. B. C.; SILVEIRA, A. di M.; SILVEIRA, H. P. Excesso de confiança, otimismo gerencial e os determinantes da estrutura de capital. In: ENCONTRO BRASILEIRO DE FINANÇAS, 6, 2006, Vitória, Anais ... Vitória: SBFIN, 2006.

BASSO, L. F. C.; MENDES, E. A.; KAYO, E. K. Teste da Teoria da Janela de Oportunidades para o Mercado Acionário Brasileiro. In: ENCONTRO NACIONAL DOS PROGRAMAS DE PÓS-GRADUAÇÃO EM ADMINISTRAÇÃO, 28, 2004, Curitiba, Anais ... Curitiba: EnANPAD, 2004.

BOOTH, L.; AIVAZIAN V.; DEMIRGUC-KUNT, A.; MAKSIMOVIC, V. Capital Structures in Developing Countries. The Journal of Finance, Vol. 56, Issue 1 p. 87-130 Feb. 2001. Disponível em: <http://www.worldbank.org/ research/bios/asli/capitals.pdf>. Data de acesso: 19/09/2006.

BRADLEY, Michael, JARRELL, Gregg A. e KIM, E. Han, On the Existence of an Optimal Capital Structure: Theory and Evidence, Journal of Finance, 39, Julho 1984, pp. 857-878.

BRAILSFORD, T. J.; OLIVER, B. R.; PUA, S. L. H. On the relation between wnership structure and capital structure. Accounting and Finance, Vol. 42, p. 1-26, 2002.

BRITO, R. D.; LIMA, M. R. O Que Determina a Estrutura de Capital no Brasil. . In: ENCONTRO BRASILEIRO DE FINANÇAS, 3, 2003, São Paulo, Anais ... São Paulo: SBFIN, 2003.

BRITO, G. A. S.;BATISTELLA, F. D.; CORRAR, L. J. Fatores determinantes da estrutura de capital das maiores empresas que atuam no Brasil. In: ENCONTRO BRASILEIRO DE FINANÇAS, 5, 2005, São Paulo, Anais ... São Paulo: SBFIN, 2005.

DAHER, C. E. Testes Empíricos de Teorias Alternativas sobre a Determinação da Estrutura de Capital das Empresas Brasileiras. Brasília: UnB, UFPB, UFPE, UFRN, 2004, 106 p. Dissertação (Mestrado em Ciências Contábeis) -Universidade Federal de Brasília, Brasília, 2004.

DAMODARAN, A. Finanças corporativas: teoria e prática. 2 ed. Porto Alegre: Bookman, 2004. 
FAMA, E. F.; FRENCH, K. R. Testing Tradeoff and Pecking Order Predictions about Dividends and Debt. Review of Financial Studies, 15, p. 1-33, 2002.

FASSINA, P. H.; HEIN, N.; OLINQUEVITCH, L. Um Sistema Especialista Difuso na Análise do Endividamento de Empresas. In: ENCONTRO BRASILEIRO DE FINANÇAS, 6, 2006, Vitória, Anais ... Vitória: SBFIN, 2006.

FRANK, M.Z.; GOYAL, V.K. Capital Structure Decisions. SSRN Working Paper Series. 2003a. Disponível em: <http://papers.ssrn.com/sol3/ delivery.cfm/SSRN_ID396020_

code030519500.pdf?abstractid=396020 > . Data de acesso: 19/09/2006.

FRANK, M.Z.; GOYAL, V.K. Testing the pecking order theory of capital structure. Journal of Financial Economics, Vol. 67, p. 217-248, $2003 \mathrm{~b}$.

GITMAN, L. J. Princípios de administração financeira. 7 ed. São Paulo: Harbra, 2002.

GOMES, G. L.; LEAL, R. P. C. L. Determinantes da Estrutura de Capitais das Empresas Brasileiras com Ações Negociadas em Bolsas de Valores. In: Finanças Corporativas. São Paulo: Atlas, 2001.

GREENE, W.H. Econometric Analysis. 5 ed. Upper Saddle River, NJ: Prentice Hall, 2003.

GUJARATI, D. Econometria Básica. 4 ed. São Paulo: Campus, 2006.

HARRIS, M.; RAVIV, A. The Theory of Capital Structure. The Journal of Finance, Vol.46, Issue 1, p. 297-355, Mar. 1991.

HEIJ, C.; BOER, P.; FRANSES, P. H.; KLOEK, T.; VAN DIJK, H. K. Econometric Methods with applications in business and economics. New York: Oxford University Press, 2004.

HOVAKIMIAN, A.; OPLER, T.; TITMAN, S. The Debt-Equity Choice. Journal of Finance and Quantitative Analysis, Vol. 36, p. 1-24, 2001.

HSIO, C. Benefits and limitations of panel data. Econometric Reviews, 4, 1985. p 121- 174.

HSIO, C. Analysis of Panel Data. Cambrigde University Press, Cambrigde, 1986. 
IBGE - Instituto Brasileiro e Geografia e Estatística. Agroindústria cresce 1,6\% em 2003 e a indústria em geral tem crescimento de 0,3\%. Disponível em: $<$ http://www.ibge.gov.br/home/presidencia/noticias/13022004agroindhtml.s htm > . Data de acesso: 21/09/2006.

IEDI - Instituto de Estudos para do Desenvolvimento Industrial. Carta IEDI n. 225 - A Queda da Rentabilidade Industrial. Publicada em: 15/09/2006. Disponível em: < http://www.iedi.org.br/cgi/cgilua.exe/sys/start.htm?sid=50> . Data de acesso: 19/09/2006.

JAEL, N. As maiores do agronegócio brasileiro. Disponível em: $<$ http://www.portaldoagronegocio.com.br/index.php? $\mathrm{p}=$ texto\&\&idT $=$ 763>. Data de acesso: 20/09/2006.

JOHNSTON, J.; DiNARDO, J. Métodos Econométricos. 4 ed. Portugal: McGraw-Hill. 2001.

KAYO, E K; FAMÁ, R. Teoria da Agência e Crescimento: Evidências Empíricas dos Efeitos Positivos e Negativos do Endividamento. Caderno de Pesquisas em Administração, São Paulo: Vol. 2, N o. 5 p. 1-8, 2Sem. 1997.

KLEVMARKEN, N. A. Panel studies: what can we learn from them? Introduction, European Economic Review 33, 1989. p. 523-529

KORAJCZYK, R.A.; LEVY, A. Capital Structure Choice: Macroeconomic Conditions and Financial Constraints. Journal of Financial Economics, Vol. 68, p. 75-109, 2003.

LANZANA, A. P. Relação entre disclosure e governança corporativa das empresas brasileiras. Dissertação de Mestrado em Administração, Faculdade de Economia e Administração, Universidade de São Paulo. São Paulo: FEA / USP, 2004. 154f.

LEMMON, M.L.; ZENDER, J. Debt Capacity and Tests of Capital Structure Theories. SSRN Working Paper Series. 2002. Disponível em: < http://papers.ssrn.com/sol3/delivery.cfm/SSRN_ID334780_code02092860 0.pdf?abstractid $=334780>$. Data de acesso: $19 / 09 / 2006$.

MARION, José Carlos. Análise das demonstrações contábeis. 3. ed. São Paulo: Atlas, 2005.

MARSH, P. The Choice Between Equity and Debt: An Empirical Study. The Journal of Finance, Vol.37, Issue 1, p. 121-144, Mar. 1982. 
MARTIN, D. M. L.; FORTE, D.; COSTA, A. C. F.; NAKAMURA, W. T.; CARVALHO FILHO, A. F.; AMARAL, A. C. Determinantes de estrutura de capital no mercado brasileiro análise de regressão com painel de dados no período 1999 - 2003. In: ENCONTRO BRASILEIRO DE FINANÇAS, 5, 2005, São Paulo, Anais ... São Paulo: SBFIN, 2005.

MATARAZZO, D. C. Análise Financeira de Balanços. 5. ed. São Paulo: Atlas, 1998.

MODIGLIANI, F.; MILLER, M. The Cost of Capital, Corporation Finance and the Theory of Investment. American Economic Review, 48, Junho 1958, p. 261-297.

MODIGLIANI, F.; MILLER, M. H. Corporate Income Taxes and the Cost of Capital: A Correction. American Economic Review, 53, Junho 1963, p. 433-443.

MORAES, E. G.; RHODEN, M. I. S. Determinantes da estrutura de capital das empresas listadas na Bovespa. In: ENCONTRO NACIONAL DOS PROGRAMAS DE PÓS-GRADUAÇÃO EM ADMINISTRAÇÃO, 29, 2005, Brasília, Anais ... Brasília: EnANPAD, 2005.

MYERS, S. C. Determinants of Corporate Borrowing. Journal of Financial Economics, Vol. 5, p. 147-175, 1977.

MYERS, S.C. The capital structure puzzle. Journal of Finance, Chicago: American Finance Association, v.39, n.3, Jul.1984.

MYERS, S.C.; MAJLUF, N. Corporate Financing and Investment Decisions When Firms Have Informations that Investors do not Have. Journal of Financial Economics, Vol. 13, p. 187-221, 1984.

MYERS, S.C. e SUNDER, L. S. Testing Static Tradeoff Against Pecking Order Models of Capital Structure. Journal of Financial Economics, 51, Fevereiro 1999, pp. 219- 244.

NAKAMURA, W. T.; MARTIN, D. M. L.; KIMURA, H. Indicadores Contábeis como Determinantes do Endividamento das Empresas Brasileiras. In: ENCONTRO NACIONAL DOS PROGRAMAS DE PÓS-GRADUAÇÃO EM ADMINISTRAÇÃO, 28, 2004, Curitiba, Anais ... Curitiba: EnANPAD, 2004. 
OLIVEIRA, L.; ANTONIALLI, L. M. Uso da estrutura de capital por empresas agroindustriais. Revista Organizações Rurais e Agroindustriais. v.6, n.2, julho/dezembro 2004. p. 134-148.

RAJAN, R. G.; ZINGALES, L. What do we know about capital structure? Some evidence from international data. The Journal of Finance, Vol 50, Issue 5, p. 1421-1460. Dec. 1995.

ROSS, S. A.; WESTERFIELD, R. W.; JAFFE, J. E. Administração Financeira: Corporate Finance. 2 ed. São Paulo: Atlas, 2002.

SANTANA, J. R.; TUROLLA, F. Escolha da Estrutura de Capital: Aplicação ao Caso do Setor Petroquímico Brasileiro no Período 1991-2000. In: ENCONTRO NACIONAL DOS PROGRAMAS DE PÓS-GRADUAÇÃO EM ADMINISTRAÇÃO, 26, 2002, Salvador, Anais ... Salvador: EnANPAD, 2002.

SOARES, R. O.; KLOECKNER, G. O. O Pecking Order em empresas com controle acionário definido: Um estudo no ambiente brasileiro. In: ENCONTRO NACIONAL DOS PROGRAMAS DE PÓS-GRADUAÇÃO EM ADMINISTRAÇÃO, 29, 2005, Brasília, Anais ... Brasília: EnANPAD, 2005.

SOLON, G. S. The value of panel data in economic research. In: D. Kasprzyk, G. J.; Duncan, G. Kalton and M. P. Singh, eds. Panel Surveys. John Wiley, New York, 1989. p. 486-496.

SRB - Sociedade Rural Brasileira. Rural Notas: Árabes estão entre os 30 maiores compradores do agronegócio Brasileiro. Disponível em: <http://www.srb.org.br>. Data de acesso: 20/09/2006.

TERRA, P. R. S. An Empirical Investigation on the Determinants of Capital Structure in Latin América. In: ENCONTRO NACIONAL DOS PROGRAMAS DE PÓS-GRADUAÇÃO EM ADMINISTRAÇÃO, 26, 2002, Salvador, Anais ... Salvador: EnANPAD, 2002.

TITMAN, S.; WESSELS, R. The Determinants of Capital Structure Choice. The Journal of Finance, Vol. 43, No.1, p. 1-19, Mar. 1988.

WESTON, J. F.; BRIGHAM, E. Fundamentos da Administração Financeira. 10 ed. São Paulo: Makron Books, 2000. 